\title{
Pancreatic Volumetric Assessment as a Predictor of New-Onset Diabetes Following Distal Pancreatectomy
}

\author{
Sachiyo Shirakawa Ippei Matsumoto $\cdot$ Hirochika Toyama \\ Makoto Shinzeki • Tetsuo Ajiki • Takumi Fukumoto • Yonson Ku
}

Received: 3 June 2012 / Accepted: 19 September 2012 /Published online: 28 September 2012

(C) 2012 The Author(s). This article is published with open access at Springerlink.com

\begin{abstract}
Introduction Pancreatogenic diabetes after pancreatectomy is of growing importance due to the increasing life expectancy of pancreatectomized patients. Although reduction of pancreatic volume is thought to affect glucose metabolism, a consistent relationship has yet to be determined. This study aimed to investigate functional consequences of distal pancreatectomy (DP) in preoperatively non-diabetic patients.

Methods This study included 61 non-diabetic patients who underwent DP. Clinical data were obtained, and the percent resected volume (PRV) of each pancreas was determined via multi-detector row computed tomography volumetry.

Results During the follow-up period (median 26 months), 22 patients (36\%) developed new-onset diabetes within a median onset time of 8 months (range 0.5-42 months) postoperatively. The remaining 39 patients also showed impaired glucose metabolism. Multivariate analysis identified preoperative hemoglobin A1c $\geq 5.7 \%$ (odds ratio 15.6, $p=0.001$ ) and PRV > $44 \%$ (odds ratio $11.3, p=0.004$ ) as independent risk factors for new-onset diabetes.

Conclusions Key determinants of postoperative glycemic control include preoperative functional reserve of the endocrine pancreas and the volume reduction of pancreatic parenchyma. Our findings enable reliable preoperative evaluation of the risk of postoperative diabetes and appropriate postoperative surveillance, which is helpful for early intervention in high risk patients.
\end{abstract}

Keywords Pancreas $\cdot$ Volumetry $\cdot$ Pancreatic diabetes

\section{Introduction}

Pancreatogenic diabetes, classified as type $3 \mathrm{c}$ by the American Diabetes Association, ${ }^{1}$ is associated with diseases of the exocrine pancreas including pancreatitis, benign and malignant neoplasm, cystic fibrosis, hemochromatosis, fibrocalculous pancreatopathy, and trauma and pancreatectomy. Among the $8-9 \%$ of the general diabetes population with type $3 \mathrm{c}$ diabetes in Western countries, $2-3 \%$ are those

No grant support was provided for this study.

S. Shirakawa $\cdot$ I. Matsumoto $(\bowtie) \cdot H$. Toyama $\cdot$ M. Shinzeki

T. Ajiki $\cdot$ T. Fukumoto $\cdot$ Y. Ku

Division of Hepato-Biliary-Pancreatic Surgery, Department of

Surgery, Kobe University Graduate School of Medicine,

7-5-2 Kusunoki-cho, Chuo-ku,

Kobe, Hyogo 650-0017, Japan

e-mail: imatsu@med.kobe-u.ac.jp who underwent pancreatectomy. ${ }^{2,3}$ Pancreatectomized patients are at high risk for type $3 \mathrm{c}$ diabetes, as well as type 2 , because surgery inevitably results in a deficit in the exocrine and endocrine pancreas, and also can promote the progression of underlying disease. Due to improved diagnostic modalities and a more refined understanding of pancreatic neoplasm pathogenesis, pancreatectomies for benign or low-grade malignant tumors are more frequent, and the life expectancy of patients undergoing pancreatectomy has increased in recent years. As the frequency of pancreatectomy and length of life expectancy increase, so does the importance of the risk of pancreatogenic diabetes associated with pancreatic surgery.

Distal pancreatectomy (DP) is the standard procedure used for removal of lesions in the body and tail of the pancreas. Long-term disturbances in glucose metabolism are a major concern after DP because previous studies have found that postoperative diabetes develops in from 4.8 to $38 \%$ of patients after DP. ${ }^{4-8}$ Physiological factors reported to correlate with postoperative pancreatic endocrine function include preoperative fasting plasma glucose (FPG), body mass index 
(BMI), and postoperative complications. ${ }^{9-11}$ Limitations in these studies, such as unspecified preoperative diabetic status of the patients and inconsistent standards used for the diagnosis of postoperative diabetes, make it difficult to reliably identify risk factors for postoperative diabetes.

Although the mass of pancreatic beta cells has been identified as an important determinant of plasma glucose levels in rodents, dogs, monkeys, and humans, ${ }^{12-15}$ to our knowledge, very few studies have directly investigated the volume reduction of human pancreatic parenchyma as a risk factor for diabetes, and no previous study systematically quantified resection volumes in a population of patients. To study potential risk factors for new-onset diabetes in preoperatively non-diabetic patients, we sought to reliably quantify the volume reduction of human pancreatic parenchyma and to determine its longitudinal metabolic consequences following DP using multi-detector row computed tomography (MDCT) imaging volumetry.

\section{Methods}

\section{Patients}

A series of 98 consecutive patients who underwent DP at our institution between January 2005 and December 2011 was originally chosen from our prospectively maintained clinical database for this retrospective study. Data from 37 (38\%) of these candidates were excluded due to preoperative diabetes, as defined either by the WHO criteria of $\mathrm{FPG} \geq 126 \mathrm{mg} / \mathrm{dl}$ detected on two or more separate days, or this abnormal FPG level detected once and plasma glucose $\geq$ $200 \mathrm{mg} / \mathrm{dl}$ measured $2 \mathrm{~h}$ after a 75-g glucose drink, or based on their treatment with oral anti-diabetic agents or insulin. The final study population consisted of 61 non-diabetic patients who had undergone DP.

Clinical data on pre- and postoperative patient status were obtained from existing medical records. Family histories of type 2 diabetes in first-degree relatives were also obtained. The preoperative data used for this study had been recorded within 14 days prior to surgery. Nutritional status and pancreatic endocrine functions were assessed based on measurements of body weight, serum albumin, FPG, and serum hemoglobin A1c (HbA1c). HbA1c values represent the National Glycohemoglobin Standardization Program (NGSP) equivalent values (in percent) and in all cases were converted from previous Japan Diabetes Society standard substance and measurement methods (JDS HbA1c, in percent) using the following formula: NGSP HbA1c (\%)=JDS HbAlc $(\%)+0.4 \%$. The percent resected volume (PRV) of pancreatic parenchyma, excluding tumor volume, was determined from abdominal MDCT measurements. Patient data were collected until the time of diagnosis of new- onset diabetes or tumor recurrence. All 61 patients were followed up for at least 3 months.

For evaluating postoperative course, we defined and graded postoperative pancreatic fistula (POPF) using the classification methods of the International Study Group of Pancreatic Fistula, ${ }^{16}$ with POPF grade B or C defined as clinically important pancreatic fistula. Postoperative complications were designated as level I to $\mathrm{V}$ based on the Clavien classification. ${ }^{17}$

\section{Determination of PRV of the Pancreatic Parenchyma}

PRVs were determined retrospectively, using preoperative MDCT images in all patients. Continuous 0.8-mm 64-row MDCT images were acquired following administration of intravenous contrast material prior to surgery. MDCT data were transferred to a computer workstation (Aquarius; Elk, Osaka, Japan) for measurement of pancreas volume. To delineate the actual pancreatic resection lines, we compared preoperative CT with postoperative CT.

Excluding tumors, cystic lesions, any dilation in the pancreatic duct and bile duct, and vessels, we outlined the borders of the pancreatic parenchyma and the resection lines on every CT slice, and we then computed the resected and remnant areas of pancreatic parenchyma for each slice (Fig. 1). The volume (in milliliters) of the pancreatic parenchyma per slice was calculated as the product of the pancreas area (in square millimeters) times the slice thickness (in millimeters). Resected and remnant volumes of the pancreatic parenchyma were computed as the sum of the slice volumes. PRV was determined using the following formula: $P R V(\%)=[$ resected volume of normal pancreas $\div$ total volume of normal pancreas] $\times 100$. PRV was calculated in 52 cases.

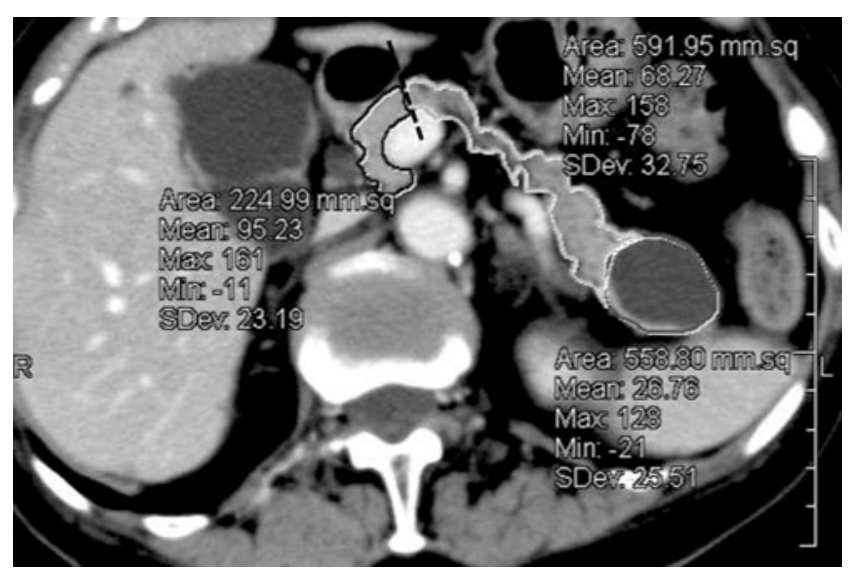

Fig. 1 MDCT pancreas volumetry. Outlined areas are the remnant parenchyma (black outline), resected parenchyma (light gray outline), and tumor (dark grey outline), excluding vessels. The dashed line is the pancreatic resection line. To determine percent resected volume, the volume (in milliliters) of the pancreatic parenchyma per slice was calculated as the product of the pancreas area (in square millimeters) times the slice thickness (in millimeters) 
In the remaining nine cases, this value could not be measured accurately because of pancreatic edema or tumors with unclear borders that had invaded peri-pancreatic organs.

\section{Definition of Postoperative New-Onset Diabetes}

Postoperative new-onset diabetes was diagnosed retrospectively based on the WHO criteria of $\mathrm{FPG} \geq 126 \mathrm{mg} / \mathrm{dl}$ detected on two or more separate days, or this abnormal FPG level detected once and plasma glucose $\geq 200 \mathrm{mg} / \mathrm{dl}$ measured in $2 \mathrm{~h}$ after a 75 -g glucose drink. The onset day of diabetes was defined as the latter day on which abnormal blood test results were detected. In this study population, no patient was administered anti-diabetic therapy with oral agents or insulin before the development of diabetes, as defined by the criteria of this study.

\section{Statistical Analysis}

Patient characteristics are reported as means \pm standard deviation (SD), and results are presented as means \pm standard error (SE) or, where indicated, medians (range). Categorical variables are expressed numerically as percentages. For analyses of repeated measurements of body weight, serum albumin, FPG, and serum HbA1c prior to and 3, 6, and 12 months after surgery, we used an analysis of variance (ANOVA) and the Mauchly test, which evaluates the sphericity assumption. We used the Student's $t$ test or MannWhitney test for continuous variables and Fisher's exact test for categorical variables. A multiple logistic regression analysis yielding odds ratios and $95 \%$ confidence intervals (CIs) was used to identify risk factors for postoperative new-onset diabetes (with $p<0.05$ ). The optimal HbA1c and PRV cutoffs for predicting the occurrence of postoperative new-onset diabetes were estimated using receiver operating characteristic (ROC) curves. All analyses were performed using JMP 9.0 for Macintosh (SAS Institute Inc, Cary, NC, USA).

\section{Results}

\section{Patients' Characteristics}

Physiological characteristics of the study patients are outlined in Table 1. While no patient met the WHO criteria for diabetes preoperatively, nine had impaired fasting glucose (IFG), defined as FPG of $110-125 \mathrm{mg} / \mathrm{dl}$. The indications for DP included pancreatic tumors in 55 of the 61 patients (90\%, 25 malignant and 30 benign tumors), alcoholinduced chronic pancreatitis in three patients, autoimmune pancreatitis mimicking pancreatic cancer in two patients, and a pseudocyst following acute pancreatitis in one patient.
Table 1 Clinical characteristics of 61 non-diabetic patients who underwent distal pancreatectomy

\begin{tabular}{ll}
\hline Male patients & $24(39)$ \\
Age (years) & $62 \pm 14$ \\
BMI (kg/m²) & $21.2 \pm 3.8$ \\
Preoperative HbA1c (\%) & $5.8 \pm 0.41$ \\
Preoperative IFG & $9(16)$ \\
Preoperative albumin (mg/dl) & $4.0 \pm 0.64$ \\
Preoperative total cholesterol (mg/dl) & $182 \pm 45$ \\
Preoperative pancreatic alpha-amylase (IU/l) & $59(4-264)$ \\
Operative time (min) & $333 \pm 88$ \\
Intraoperative blood loss (ml) & $427(5-3524)$ \\
Malignancy & $25(41)$ \\
Percent resected volume (\%) & $38 \pm 17$ \\
POPF $\geq$ grade B & $16(26)$ \\
Postoperative complication $\geq$ Clavien's grade II & $22(36)$ \\
Postoperative hospital stay (days) & $18(7-58)$ \\
Mortality (\%) & 0 \\
\hline
\end{tabular}

Values are means $\pm \mathrm{SD}$, medians (range), or $n(\%)$

$H b A 1 c$ hemoglobin A1c, IFG impaired fasting glucose, $F P G$ fasting plasma glucose, $P O P F$ postoperative pancreatic fistula

Three patients had a first-degree family history of type 2 diabetes.

\section{Pancreas Volumetry}

MDCT imaging volumetric data showed a wide range of volumes of whole, remnant, and resected pancreatic parenchyma and of tumors in patients with or without new-onset diabetes (Table 2). While the mean PRV for all 61 cases was $38 \%$ (range 9-85\%), the mean PRV for the new-onset diabetes group was $49 \%$, which was significantly higher than the PRV of $32 \%$ for the non-diabetic group.

Sequential Changes in Diabetic and Nutritional Status After Surgery

We compared four physiological parameters in new-onset diabetic versus non-diabetic patients at four time points: before and 3, 6, and 12 months after surgery. Three months after surgery, there were significant increases in FPG and HbAlc in both groups (Table 3). Disturbances in glucose control occurred within the first 3 months after surgery, and did not significantly progress after that time in either group.

During the post-DP follow-up period (median 26 months, range 3-88 months), 22 patients (36\%) developed newonset diabetes (median onset time 8 months, range 0.5 42 months). In most of the 39 patients without new-onset diabetes, FPG and HbA1c increased significantly during the follow-up period; however, values remained stable in eight 
Table 2 CT volumetry in DP patients

\begin{tabular}{|c|c|c|c|c|}
\hline & All patients & New-onset diabetes group & No new-onset diabetes group & $p$ value \\
\hline Number of patients with PRV data & 52 & 20 & 32 & \\
\hline Whole normal parenchyma $(\mathrm{ml})$ & $56.6(16.0-128.2)$ & $54.6(27.0-89.4)$ & $56.6(16.0-128.2)$ & 0.58 \\
\hline Remnant normal parenchyma (ml) & $36.5(4.4-116.4)$ & $25.1(4.4-65.8)$ & $38.6(6.6-116.4)$ & 0.047 \\
\hline Resected normal parenchyma (ml) & $18.7(3.5-57.7)$ & $25.8(9.9-57.7)$ & $16.5(3.5-55.3)$ & 0.004 \\
\hline Tumor or cystic lesion (ml) & $5.4(0-543.7)$ & $4.1(0-38.7)$ & $7.4(0.2-543.7)$ & 0.11 \\
\hline PRV (\%) & $38 \pm 17(9-85)$ & $49 \pm 15(20-85)$ & $32 \pm 15(9-59)$ & $<0.001$ \\
\hline
\end{tabular}

Values are medians (range) or means \pm SD (range). $p$ values were obtained using Mann-Whitney $U$ test, except for use of Student's $t$ test for PRV $C T$ computed tomography, $D P$ distal pancreatectomy

of these 39 patients (change in $\mathrm{HbA} 1 \mathrm{c} \leq 0.1 \%$ ), and one patient displayed improvement in glycemic control, as exhibited by a $0.4 \%$ decrease in HbAlc.

While we observed significant between-group differences in the changes in FPG (Fig. 2a) $(p=0.003)$ and HbAlc (Fig. 2b) $(p<0.001)$ over time, there were no significant differences in changes in body weight (Fig. 2c) $(p=0.36)$ or serum albumin (Fig. 2d) $(p=0.58)$. Because Mauchly tests for the sphericity assumption were not significant for these factors $(P=0.21,0.82,0.28$, and 0.30 , respectively), the reported $p$ values are for univariate ANOVA.

\section{Risk Factors for Postoperative New-Onset Diabetes}

Univariate analyses identified three statistically significant risk factors for postoperative new-onset diabetes: preoperative $\mathrm{HbA} 1 \mathrm{c} \geq 5.7 \%, \mathrm{PRV}>44 \%$, and age (Table 4). Multivariate logistic regression analysis also identified $\mathrm{HbAlc} \geq$ $5.7 \%$ [odds ratio 15.6 (95\% CI 2.80-147), $p=0.001$ ] and PRV $>44 \%$ [odds ratio 11.3 (95\% CI 2.12-92.1), $p=0.004$ ] as independent risk factors for postoperative new-onset diabetes (Table 5). Regarding family history, one of three patients with first-degree family history of type 2 diabetes, of whom PRV was $85 \%$, developed new-onset diabetes at 2 months after surgery. We assessed the sensitivity and specificity of the HbA1c and PRV parameters using the ROC curves. The areas under the ROC curves were 0.831 for $\mathrm{HbAlc}$ and 0.793 for PRV. Using these curves, HbAlc of $5.7 \%$ and PRV of $44 \%$ were determined to be the cutoffs for predicting the occurrence of postoperative diabetes. The sensitivity, specificity, and positive and negative predictive values derived from these curves were $0.82,0.64,0.56$, and 0.86 for $\mathrm{HbA} 1 \mathrm{c}$ and $0.75,0.81,0.71$, and 0.84 for PRV, respectively.

\section{Discussion}

We report here two major findings from this study of patients who underwent DP. First, in the majority of preoperatively non-diabetic patients, DP led to disturbances in glucose metabolism, and there was a $36 \%$ incidence of

Table 3 FPG and serum HbA1c before and 3, 6, and 12 months after surgery

\begin{tabular}{llllll}
\hline & $\begin{array}{l}\text { All patients } \\
(n=61)\end{array}$ & $p$ value & $\begin{array}{l}\text { New-onset diabetes } \\
\text { group }(n=22)\end{array}$ & $p$ value & $\begin{array}{l}\text { No new-onset diabetes } \\
\text { group }(n=39)\end{array}$ \\
\hline FPG (mg/dl) & & & & $93 \pm 1.9$ \\
Before surgery & $96 \pm 1.9$ & & $101 \pm 3.8$ & $0.008^{\mathrm{a}}$ & $102 \pm 2.6$ \\
3 months after surgery & $109 \pm 2.8$ & $<0.001^{\mathrm{a}}$ & $121 \pm 5.3$ & $0.17^{\mathrm{b}}$ & $99 \pm 2.4$ \\
6 months after surgery & $111 \pm 4.9$ & $0.29^{\mathrm{b}}$ & $133 \pm 11.6$ & $0.15^{\mathrm{b}}$ & $100 \pm 3.0$ \\
12 months after surgery & $114 \pm 5.8$ & $0.19^{\mathrm{b}}$ & $137 \pm 12.2$ & & $0.006^{\mathrm{a}}$ \\
HbA1c (\%) & & & & $5.6 \pm 0.06$ \\
Before surgery & $5.8 \pm 0.05$ & & $6.1 \pm 0.06$ & $0.003^{\mathrm{a}}$ & $5.9 \pm 0.07$ \\
3 months after surgery & $6.2 \pm 0.10$ & $<0.001^{\mathrm{a}}$ & $6.7 \pm 0.19$ & $0.81^{\mathrm{b}}$ & $5.9 \pm 0.07$ \\
6 months after surgery & $6.3 \pm 0.24$ & $0.73^{\mathrm{b}}$ & $7.0 \pm 0.51$ & $0.49^{\mathrm{b}}$ & $5.9 \pm 0.06$ \\
12 months after surgery & $6.4 \pm 0.18$ & $0.13^{\mathrm{b}}$ & $7.1 \pm 0.36$ & $0.002^{\mathrm{a}}$ \\
\hline
\end{tabular}

Values are means \pm SE. Data were analyzed using Student's paired $t$ test for each group

${ }^{\text {a }}$ Differences compared to values before surgery

${ }^{\mathrm{b}}$ Differences compared to values at 3 months after surgery 

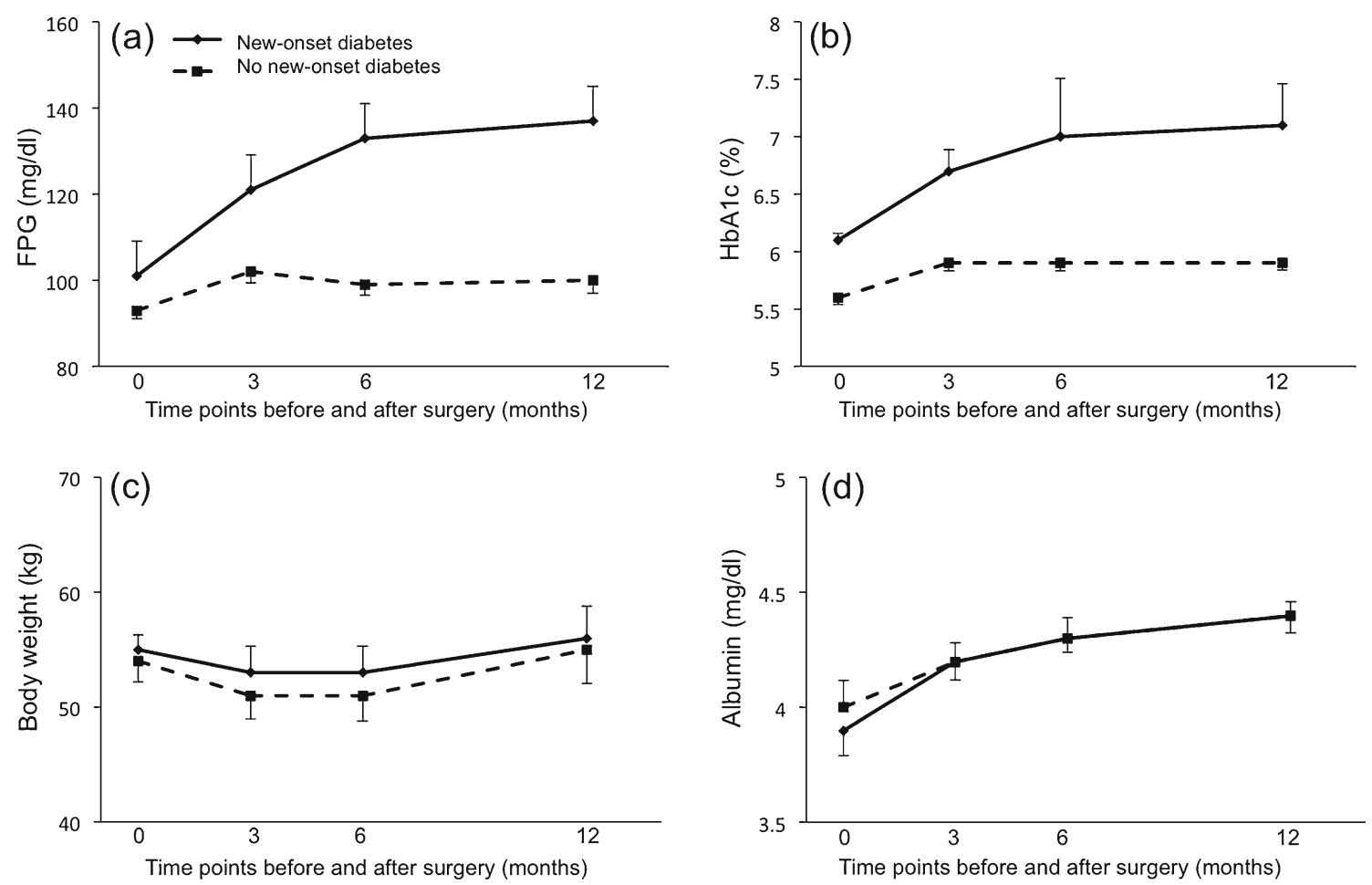

Fig. 2 Changes in parameters before and 3, 6, and 12 months after surgery: a FPG, b HbA1c, c body weight, and $\mathbf{d}$ serum albumin. Values from patients who developed new-onset diabetes (solid lines) were compared with non-diabetic patients (dashed lines) using ANOVA, with evaluation of the sphericity assumption by the Mauchly test.

new-onset diabetes postoperatively. Second, in DP patients, PRV and preoperative HbAlc were independent risk factors for new-onset diabetes.

Our results enable us to provide evidence-based preoperative counseling and individualized postoperative surveillance. Prior to surgery, we can now offer patients specific information about their individual risk of postoperative diabetes. Postoperatively, appropriate surveillance may detect the development of impaired glucose metabolism [i.e., impaired glucose tolerance (IGT), IFG, and diabetes] at an early stage and enable early intervention. Intensive glucose control has been reported to decrease the risks of major cardiovascular events and death in patients with newly diagnosed type 2 diabetes. ${ }^{18}$ Also, in patients with IGT who are pre-diabetic, the early introduction of anti-diabetic agents has been reported to diminish the development of type 2 diabetes. ${ }^{19}$ The American Diabetes Association recommends intensive annual monitoring, lifestyle modification, and sometimes use of anti-diabetic agents in patients with IGT, IFG, or HbA1c of 5.7-6.4\% for the prevention and delay of developing type 2 diabetes. ${ }^{20}$ Therefore, early detection and intervention for endocrine insufficiency are essential for DP patients.

Prior reports have estimated the incidence of new-onset diabetes after DP at between 9 and $38 \%$ of preoperatively

Postoperatively, there were significant between-group differences in changes in FPG $(p=0.003)$ and HbA1c levels $(p<0.001)$. No significant between-group difference in body weight $(p=0.36)$ or albumin $(p=0.58)$ was observed

non-diabetic patients. ${ }^{4,6,8,21}$ The numerous limitations of these studies (such as unspecified preoperative diabetic status of study patients, inconsistent standards for diagnosis of postoperative diabetes, and selection of cohorts of patients with chronic pancreatitis) make it difficult to evaluate the basis for this wide range of diabetes incidence. In the current study, the incidence of postoperative new-onset diabetes in preoperatively non-diabetic patients was $36 \%$. We attribute this relatively high measure of incidence to our application of a definitive classification system and close follow-up.

The results of this study identify PRV $>44 \%$ as an independent risk factor for postoperative new-onset diabetes in preoperatively non-diabetic DP patients. Although beta cell mass has previously been reported to be significantly related to plasma glucose control, ${ }^{14,22,23}$ volumetric assessments in relation to postoperative endocrine function of the pancreas remain scarce. Previous studies in large animals $^{13,15}$ and humans ${ }^{22}$ have demonstrated that a $50 \%$ loss in beta cells elevates plasma glucose. The DP procedure is often referred to as a "hemi-pancreatectomy," with an estimated $50 \%$ reduction in pancreatic volume after transection on the superior mesenteric vein (SMV). ${ }^{9,11}$ In our study, the median PRV in 29 patients with transection on the SMV was $46 \%$, but we observed a wide range of values in these cases (PRV from 18 to $67 \%$ ), as well as among all 
Table 4 Univariate analysis of risk factors for postoperative new-onset diabetes
Values are means $\pm \mathrm{SE}$, medians (range) or $n(\%)$

$H b A 1 c$ hemoglobin A1c, FPG fasting plasma glucose, $P O P F$ postoperative pancreatic fistula

${ }^{\mathrm{a}} p$ values were obtained using Fisher's exact test

${ }^{\mathrm{b}} p$ values were obtained using Student's $t$ test

${ }^{c} p$ values were obtained using Mann-Whitney $U$ test

\begin{tabular}{lllc}
\hline & $\begin{array}{l}\text { New-onset } \\
\text { diabetes } \\
\text { group }(n=22)\end{array}$ & $\begin{array}{l}\text { No new-onset diabetes } \\
\text { group }(n=39)\end{array}$ & $p$ value \\
\hline Male patients & $9(41)$ & $15(38)$ & $1.00^{\mathrm{a}}$ \\
Age (years) & $67 \pm 3.0$ & $59 \pm 2.2$ & $0.025^{\mathrm{b}}$ \\
BMI (kg/m ${ }^{2}$ ) & $22 \pm 0.78$ & $20 \pm 0.59$ & $0.075^{\mathrm{b}}$ \\
Preoperative HbAlc $\geq 5.7 \%$ & $18(82)$ & $14(36)$ & $0.001^{\mathrm{a}}$ \\
Preoperative IFG & $6(27)$ & $3(8)$ & $0.059^{\mathrm{a}}$ \\
Preoperative albumin (mg/dl) & $3.9 \pm 0.13$ & $4.0 \pm 0.10$ & $0.59^{\mathrm{b}}$ \\
Preoperative total cholesterol (mg/dl) & $176 \pm 9.6$ & $186 \pm 7.3$ & $0.42^{\mathrm{b}}$ \\
Preoperative pancreatic alpha-amylase (IU/l) & $58(6-243)$ & $59(4-264)$ & $0.98^{\mathrm{c}}$ \\
Operative time (min) & $312 \pm 19$ & $347 \pm 15$ & $0.14^{\mathrm{b}}$ \\
Intraoperative blood loss (ml) & $372(5-1125)$ & $527(5-3524)$ & $0.17^{\mathrm{c}}$ \\
Malignancy & $8(36)$ & $17(44)$ & $0.79^{\mathrm{a}}$ \\
PRV $>44 \%$ & $15(75)$ & $6(19)$ & $<0.001^{\mathrm{a}}$ \\
POPF $\geq$ grade B & $6(27)$ & $10(26)$ & $1.00^{\mathrm{a}}$ \\
Postoperative complication $\geq$ Clavien's grade II & $7(32)$ & $15(38)$ & $0.78^{\mathrm{a}}$ \\
Postoperative hospital stay (days) & $16(7-54)$ & $18(7-58)$ & $0.60^{\mathrm{c}}$ \\
Adjuvant chemotherapy & $7(32)$ & $15(38)$ & $0.78^{\mathrm{a}}$ \\
\hline
\end{tabular}

cases of DP (PRV from 9 to $85 \%$ ). Variations in PRV can also be attributed to differences in the patients' pancreatic sizes and shapes, as well as differences in pancreatic tumor characteristics (i.e., location and the involvement of the main pancreatic duct that causes atrophy of the distal pancreas). Our use of MDCT-based measurements of pancreas volume resulted in more precise PRV values and thereby provides evidence that greater resection of pancreatic tissue increases the incidence of new-onset diabetes in preoperatively non-diabetic DP patients. Thus, although pancreatic resection must be tailored to suit the tumor character (benign or malignant), location, and extent of tumor invasion, our data suggest that parenchyma-sparing pancreatectomies (such as middle pancreatectomy or tumor enucleation) are more likely to maintain postoperative pancreatic endocrine function and reduce the risk of diabetes.

In this study, we frequently observed a delay in diabetes onset in the 22 new-onset diabetics (median time 8 months, range $0.5-42$ months), with only five showing signs of

Table 5 Multivariate logistic regression analysis of risk factors for postoperative new-onset diabetes

\begin{tabular}{llll}
\hline & Odds ratio & $95 \%$ CI & $p$ value \\
\hline Age & $1.03^{\mathrm{a}}$ & $0.96-1.11$ & 0.42 \\
Preoperative IFG & 1.52 & $0.18-14.7$ & 0.69 \\
Preoperative HbA1c $\geq 5.7 \%$ & 15.6 & $2.80-147$ & 0.001 \\
PRV $>44 \%$ & 11.3 & $2.12-92.1$ & 0.004 \\
\hline
\end{tabular}

${ }^{\text {a }}$ Odds ratio by 1 year post-DP diabetes within 3 months. However, both groups of DP patients displayed significant increases in FPG and $\mathrm{HbAlc}$ levels within 3 months following surgery, but without further increases thereafter. These data lead us to hypothesize that, while surgical reduction of pancreatic parenchyma volume quickly impairs glucose metabolism, the observed lag in diabetes onset depends on other factors, such as the amount and overall health of the remaining endocrine pancreas that control plasma glucose.

In patients with insufficient functional reserve of the remnant pancreas to compensate for beta cell deficit (with severity depending on the volume of the pancreas removed), overt diabetes would develop in the early postoperative period (within 3 months postoperatively). The functional reserve of the endocrine pancreas could be estimated based on the preoperative $\mathrm{HbAlc}$ value, which was identified as a risk factor predictive of postoperative diabetes in this study. In patients with late-onset diabetes (later than 3 months after surgery), beta cell compensation would considerably influence the diabetes onset time. In the field of islet cell transplants, although obese individuals are generally at high risk of diabetes, it has been reported that the high demand for insulin in obese donors without diabetes promotes the necessary increase in islet cell hypertrophy and proliferation. ${ }^{24}$ Islet cells that remain after pancreatectomy are likely in a similar situation that stimulates islet hypertrophy and thus a compensatory increase in insulin secretion in the endocrine pancreas. Eventually, however, this pre-diabetic state may progress to overt diabetes once the endocrine pancreas is exhausted and fails to control glucose homeostasis. Also, 
additional factors that vary the timing of late-onset postoperative diabetes include normal progression of underlying diseases, such as pancreatitis, as well as acquired risk factors for type 2 diabetes (e.g., weight gain or aging).

Our analyses identified preoperative $\mathrm{HbA} 1 \mathrm{c}$ as a second risk factor for postoperative new-onset diabetes. $\mathrm{HbAlc}$ is increasingly viewed as a superior index of chronic hyperglycemia relative to plasma glucose (which varies during the day), and the American Diabetes Association recently added $\mathrm{HbA} 1 \mathrm{c} \geq 6.5 \%$ to its diagnostic criteria for the detection of early diabetes, with slightly lower HbA1c values (from 5.7 to $6.4 \%$ ) categorized as signaling an increased risk of diabetes. ${ }^{1}$ In our study, the cutoff value at which HbA1c became a risk factor was $5.7 \%$. Among the study's 61 patients (none of whom met the WHO criteria for diabetes, $\mathrm{FPG} \geq 126 \mathrm{mg} / \mathrm{dl}$ ), preoperative $\mathrm{HbA} 1 \mathrm{c}$ was $\geq 6.5 \%$ in two patients and between 5.7 and $6.4 \%$ in another 30 patients. Of these 32 individuals, 18 patients (56\%) developed postoperative diabetes. However, it is noteworthy that four additional patients with $\mathrm{HbAlc}<5.7 \%$, but relatively high PRV (from 47 to $61 \%$ ), also developed diabetes.

The metabolic consequences of pancreatic resection are multifaceted and can be affected by glucoregulatory hormone concentrations, the balance between production and utilization of glucose, changes in insulin sensitivity and nutritional status, surgical complications, ${ }^{25,26}$ and tumor character (malignant or benign). Despite decreases in insulin secretion, some studies have reported post-pancreatectomy improvements in glucose control in malignant cases. ${ }^{27,28}$ Because malignant pancreatic tumors are known to produce substances that impair the action of insulin and decrease insulin sensitivity, a patient's diabetic status can sometimes improve after tumor removal. ${ }^{29,30}$ Of the nine patients in our study who showed stable glycemic control (eight with HbAlc $\leq 0.1 \%$ ) or improved control (one with HbAlc reduced by $0.4 \%$ ) during the post-DP follow-up period, five had malignant tumors. The one patient with improved glycemic control had a highly advanced cancer, as well as preoperative $\mathrm{HbA} 1 \mathrm{c}$ and BMI levels of $6.2 \%$ and $28.7 \mathrm{~kg} /$ $\mathrm{mm}^{2}$, respectively, indicating pre-diabetes. This patient lost $13 \%$ of his body weight within 3 months after surgery, and it is likely that this loss helped suppress the progression of type 2 diabetes. Our results did not demonstrate any influence of malignant tumors on postoperative endocrine function.

\section{Conclusion}

Adequate preoperative functional reserve of the endocrine pancreas $(\mathrm{HbA} 1 \mathrm{c}<5.7 \%)$ and maximizing the volume of the pancreatic parenchyma preserved are two key determinants of successful postoperative glycemic control. Our findings enable reliable preoperative evaluation of the risk of developing diabetes and to perform postoperative surveillance appropriately. Late-onset diabetes needs to be recognized as a common sequela of DP, and longitudinal followup and preventive intervention (weight control and antidiabetic agents for pre-diabetic patients) should be introduced in high-risk patients.

Open Access This article is distributed under the terms of the Creative Commons Attribution License which permits any use, distribution, and reproduction in any medium, provided the original author(s) and the source are credited.

\section{References}

1. Diagnosis and classification of diabetes mellitus. Diabetes Care 2012; 35 Suppl 1: S64-71.

2. Ewald N, Kaufmann C, Raspe A, Kloer HU, Bretzel RG, Hardt PD. Prevalence of diabetes mellitus secondary to pancreatic diseases (type 3c). Diabetes Metab Res Rev 2011; 28: 338-42.

3. Hardt PD, Brendel MD, Kloer HU, Bretzel RG. Is pancreatic diabetes (type $3 \mathrm{c}$ diabetes) underdiagnosed and misdiagnosed? Diabetes Care 2008; 31 Suppl 2: S165-169.

4. King J, Kazanjian K, Matsumoto J, Reber HA, Yeh MW, Hines OJ, Eibl G. Distal pancreatectomy: incidence of postoperative diabetes. J Gastrointest Surg 2008; 12: 1548-1553.

5. Crippa S, Bassi C, Warshaw AL, Falconi M, Partelli S, Thayer SP, Pederzoli P, Fernandez-del Castillo C. Middle pancreatectomy: indications, short- and long-term operative outcomes. Ann Surg 2007; 246: 69-76.

6. Shikano T, Nakao A, Kodera Y, Yamada S, Fujii T, Sugimoto H, Kanazumi N, Nomoto S, Takeda S. Middle pancreatectomy: safety and long-term results. Surgery 2010; 147: 21-29.

7. DiNorcia J, Ahmed L, Lee MK, Reavey PL, Yakaitis EA, Lee JA, Schrope BA, Chabot JA, Allendorf JD. Better preservation of endocrine function after central versus distal pancreatectomy for mid-gland lesions. Surgery 2010; 148: 1247-1254; discussion 1254-1246.

8. Riediger H, Adam U, Fischer E, Keck T, Pfeffer F, Hopt UT, Makowiec F. Long-term outcome after resection for chronic pancreatitis in 224 patients. J Gastrointest Surg 2007; 11: 949-959.

9. Menge BA, Schrader H, Breuer TG, Dabrowski Y, Uhl W, Schmidt WE, Meier JJ. Metabolic consequences of a $50 \%$ partial pancreatectomy in humans. Diabetologia 2009; 52: 306-317.

10. Kumar AF, Gruessner RW, Seaquist ER. Risk of glucose intolerance and diabetes in hemipancreatectomized donors selected for normal preoperative glucose metabolism. Diabetes Care 2008; 31: $1639-1643$

11. Robertson RP, Lanz KJ, Sutherland DE, Seaquist ER. Relationship between diabetes and obesity 9 to 18 years after hemipancreatectomy and transplantation in donors and recipients. Transplantation 2002; 73: 736-741.

12. Leahy JL, Bonner-Weir S, Weir GC. Abnormal glucose regulation of insulin secretion in models of reduced B-cell mass. Diabetes 1984; 33: 667-673.

13. Matveyenko AV, Veldhuis JD, Butler PC. Mechanisms of impaired fasting glucose and glucose intolerance induced by an approximate 50\% pancreatectomy. Diabetes 2006; 55: 2347-2356.

14. Meier JJ, Menge BA, Breuer TG, Muller CA, Tannapfel A, Uhl W, Schmidt WE, Schrader H. Functional assessment of pancreatic beta-cell area in humans. Diabetes 2009; 58: 1595-1603. 
15. Saisho Y, Butler AE, Manesso E, Galasso R, Zhang L, Gurlo T, Toffolo GM, Cobelli C, Kavanagh K, Wagner JD, Butler PC. Relationship between fractional pancreatic beta cell area and fasting plasma glucose concentration in monkeys. Diabetologia 2010; 53: 111-114.

16. Bassi C, Dervenis C, Butturini G, Fingerhut A, Yeo C, Izbicki J, Neoptolemos J, Sarr M, Traverso W, Buchler M. Postoperative pancreatic fistula: an international study group (ISGPF) definition. Surgery $2005 ; 138$ : 8-13.

17. Dindo D, Demartines N, Clavien P-A. Classification of Surgical Complications. Ann Surg 2004; 240: 205-213.

18. Holman RR, Paul SK, Bethel MA, Matthews DR, Neil HA. 10year follow-up of intensive glucose control in type 2 diabetes. $\mathrm{N}$ Engl J Med 2008; 359: 1577-1589.

19. Kawamori R, Tajima N, Iwamoto Y, Kashiwagi A, Shimamoto K, Kaku K. Voglibose for prevention of type 2 diabetes mellitus: a randomised, double-blind trial in Japanese individuals with impaired glucose tolerance. Lancet 2009; 373: 1607-1614.

20. Standards of medical care in diabetes - 2012. Diabetes Care 2012; 35 Suppl 1: S11-63.

21. Hutchins RR, Hart RS, Pacifico M, Bradley NJ, Williamson RC. Long-term results of distal pancreatectomy for chronic pancreatitis in 90 patients. Ann Surg 2002; 236: 612-618.

22. Ritzel RA, Butler AE, Rizza RA, Veldhuis JD, Butler PC. Relationship between beta-cell mass and fasting blood glucose concentration in humans. Diabetes Care 2006; 29: $717-$ 718 .
23. Nakamura Y, Higuchi S, Maruyama K. Pancreatic volume associated with endocrine and exocrine function of the pancreas among Japanese alcoholics. Pancreatology 2005; 5: 422-431.

24. Matsumoto I, Sawada T, Nakano M, Sakai T, Liu B, Ansite JD, Zhang HJ, Kandaswamy R, Sutherland DE, Hering BJ. Improvement in islet yield from obese donors for human islet transplants. Transplantation 2004; 78: 880-885.

25. Ishikawa $\mathrm{O}$, Ohigashi $\mathrm{H}$, Eguchi H, Yokoyama $\mathrm{S}$, Yamada $\mathrm{T}$, Takachi K, Miyashiro I, Murata K, Doki Y, Sasaki Y, Imaoka S. Long-term follow-up of glucose tolerance function after pancreaticoduodenectomy: comparison between pancreaticogastrostomy and pancreaticojejunostomy. Surgery 2004; 136: 617-623.

26. Murakami Y, Uemura K, Hayashidani Y, Sudo T, Hashimoto Y, Ohge H, Sueda T. Long-term pancreatic endocrine function following pancreatoduodenectomy with pancreaticogastrostomy. J Surg Oncol 2008; 97: 519-522.

27. Litwin J, Dobrowolski S, Orlowska-Kunikowska E, Sledzinski Z. Changes in glucose metabolism after Kausch-Whipple pancreatectomy in pancreatic cancer and chronic pancreatitis patients. Pancreas 2008; 36: 26-30.

28. Permert J, Ihse I, Jorfeldt L, von Schenck H, Arnquist HJ, Larsson J. Improved glucose metabolism after subtotal pancreatectomy for pancreatic cancer. Br J Surg 1993; 80: 1047-1050.

29. Katsumichi I, Pour PM. Diabetes mellitus in pancreatic cancer: is it a causal relationship? Am J Surg 2007; 194: S71-75.

30. Saruc M, Pour PM. Diabetes and its relationship to pancreatic carcinoma. Pancreas 2003; 26: 381-387. 